\title{
Simulation of a Production Workplace Using Virtual Reality
}

\author{
Monika Töröková, Jozef Török \\ Technical University of Kosice, Faculty of Manufacturing Technologies with \\ a seat in Presov, Bayerova 1, 08001 Prešov, Slovakia
}

\begin{abstract}
Innovations in the production process are one of the basic conditions for guaranteeing the company's long-term sustainable growth and increasing its competitiveness. The introduction and use of innovative systems and technologies is a way that will significantly influence and help achieve these goals. This paper describes a simulation of a production workplace using virtual reality. The simulation was performed in Visual Components software with HTC Vive Pro hardware.
\end{abstract}

Keywords - virtual reality, visual components, HTC Vive Pro.

\section{Introduction}

In today's rapidly evolving environment, industry faces the constant challenge of producing and creating new innovative products in the shortest possible time. This requires the introduction and use of more modern and innovative systems and technologies that will help achieve these goals. The current trend is the globalization of the production environment, which requires the exchange of information in real time between different nodes in the life cycle of product development [1].

DOI: 10.18421/TEM103-49

https://doi.org/10.18421/TEM103-49

Corresponding author: Monika Töröková,

Technical University of Kosice, Faculty of Manufacturing technologies with a seat in Presov, Prešov, Slovakia.

Email: monika.torokova@tuke.sk

Received: 12 June 2021.

Revised: 01 August 2021.

Accepted: 09 August 2021.

Published: 27 August 2021.

(cc)BY-Nc-ND (c) 2021 Töröková Monika \& Török Jozef; published by UIKTEN. This work is licensed under the Creative Commons Attribution-NonCommercial-NoDerivs 4.0 License.

The article is published with Open Access at www.temjournal.com
Ensuring collaboration between the phases of this cycle (such as design, planning, production setup, machining, assembly, etc.) are necessary mainly for reasons of efficiency and compliance with all requirements that are placed on the production process. The procedures used in the development and production of products are becoming more complex and versatile as products become more and more complex and demanding. Consideration of environmental waste, service and repair activities are also key in decision-making [2]. Decisive factors for production processes are also systematicity, the best possible efficiency, economy and competitiveness. The crucial solution is to use virtual and augmented reality to simulate and visualize processes, which usually results in their improvement before they take place. Based on the above, activities such as design, planning, design of the production workplace are carried out for the first time in computer simulations and then modified so that no further modifications and reworkings are required during implementation. Tools offering virtual reality systems have great potential in production, which is being used more and more often. These systems are used in an everwidening range in various industries where when applied correctly, they represent a significant saving of time and money [3].

\section{Application of Virtual Reality in Production Workplace Simulation}

The program Visual Components Experience was used to generate the simulation of the production workplace in virtual reality environment, which enables immersive simulation with the help of suitable hardware equipment. For this purpose, the HTC Vive Pro virtual reality set was selected, which can be used to provide this experience [4]. In addition to visualization, in order to enable interaction in the virtual reality environment with the designed production workplace, it is necessary to adapt the design in the Visual Components software (example of the environment in Figure 1.) environment to the conditions of such use in virtual reality [5],[6]. 


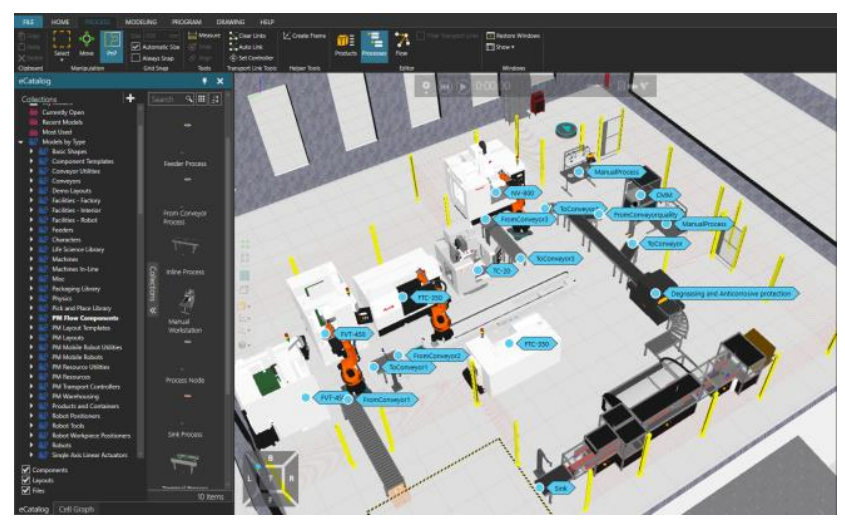

Figure 1. Production workplace

\subsection{Simulation of a Production Workplace in the VR Environment}

After the connection, the visualization of the designed production workplace in the environment of virtual reality takes place. The user wearing the HTC Vive Pro headset is located directly at the factory. HTC Vive Pro drivers are also used in virtual reality production site simulations, which are visible and represent real hand movements [7]. For the purpose of interaction with the production workplace in virtual reality environment, the buttons located on these controllers are used, where to each is assigned a certain function, namely:

1. Menu Button - displays the main menu

2. Trackpad - change the position or height of the view after pressing the top and bottom of this button either up or down

3. Shutter button - consists of two positions

- pressed gently, it is possible to see the beam, which can be aimed at the desired location

- hold the button, the selection is confirmed

4. Snap button - used to grab and then interact with the object in the simulation [8],[9].

In the main menu, which is shown in

Figure 2, the simulation of the production workplace in virtual reality was started using the play function. There are also functions such as stopping, resetting or scaling the parts of workplace [10].

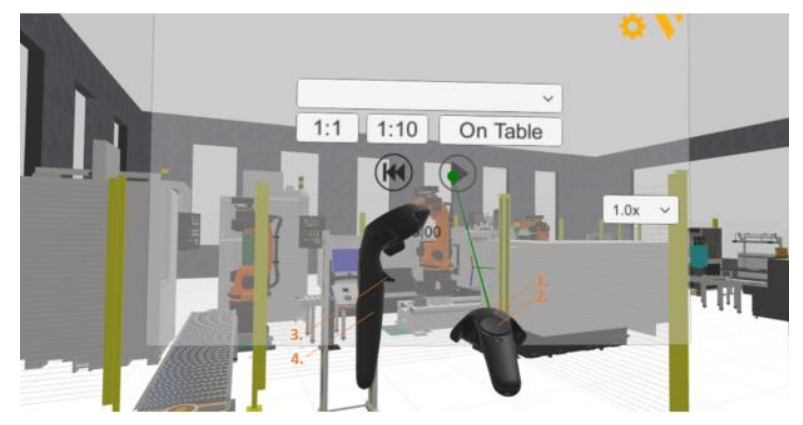

Figure 2. Start of simulation of the production workplace in VR environment
Movement or movement around the designed production workplace is enabled within the movement of the user around the space in a preprepared room in which he is located in the real world. In order to be able to get to places in the workplace in virtual reality that are not available in this way, a so-called teleport is used for this purpose. It works as shown in Figure 3,, in a virtual reality environment, where by gently pressing the shutter button on the controller, it determines the place where the user wants to get in the designed production workplace. Another full press of this button is the changed position of the user to a given place in virtual reality.

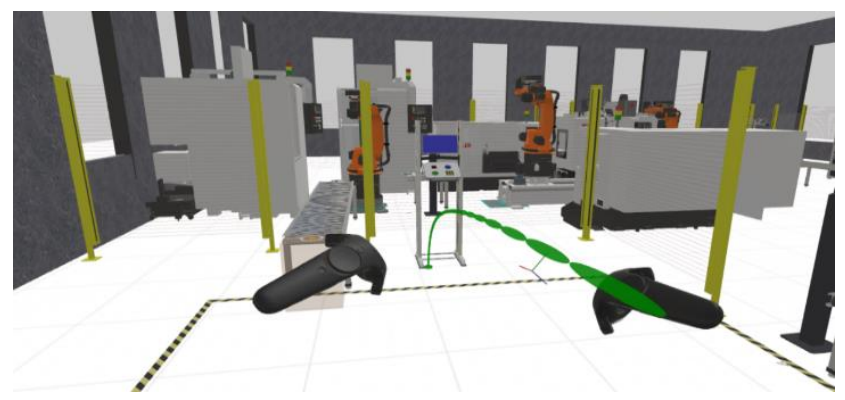

Figure 3. Movement on the proposed simulated production workplace in VR

In this way, the user can move around the production site and detect errors and collisions that could occur. In a classical simulation, which usually takes place only in 3D view, these errors and collisions may not be visible, and their detection could occur only in a real system. This could result in increased costs or a malfunction of a particular production system. By using virtual reality, these mistakes and collisions can be avoided [11],[12].

At the designed production workplace, the collision of the manipulator arm with the production machine during the first production operation was revealed, as shown in Figure 4. The robot moves into the space of the FVT-450 production machine when moving the part from the first conveyor. This bug was fixed by changing the location of this machine. This change took place in the Visual Components Premium 4.3 program without the need to turn off virtual simulation. The change in virtual reality was reflected immediately after the machine was moved. By resetting and running the simulation movements, it was verified whether there are no repeated collisions in the given production unit after the adjustment. 


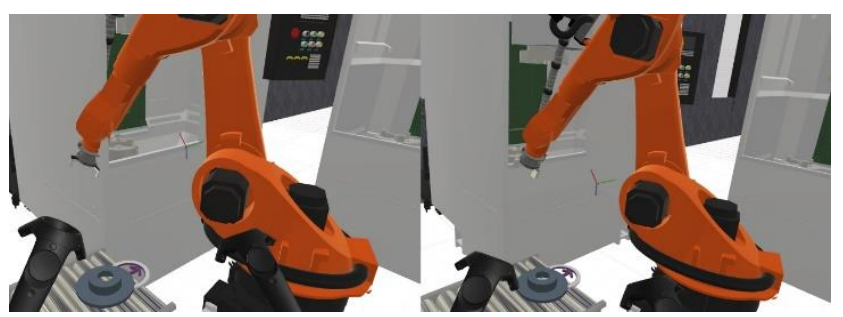

Figure 4. Robot collision

In order to avoid such collision situations before introducing a change in the workplace, it is possible in a virtual reality environment to verify with this production facility where this collision could occur and determine which element in the production system needs to be adapted, which saves time. Most often, these cases occur in moving parts of the workplace where the part is moved to the production equipment by a robot. Based on this, all robots in the workplace have been adapted to interact with controllers in virtual reality. This makes it possible to verify whether the extreme positions of these robots or their separate joints. Based on information of this type, it is possible to limit the movements of these robot joints in the simulation as required and by virtual reality testing to continuously verify these positions on the selected manipulator so that no collisions occur in the production site simulation. For the application of this method, a robot was selected in the designed production workplace, which ensured the transfer of components to the production machine NV-800 dealing with the balancing and finishing process. After moving to a suitable place near the robot in a virtual reality environment, from which it is possible to get with the controller to the desired part, after targeting the part of the robot and then pressing the grip button, it is possible to move either the whole robot or its selected part and verify certain positions. This is shown in Figure 5.

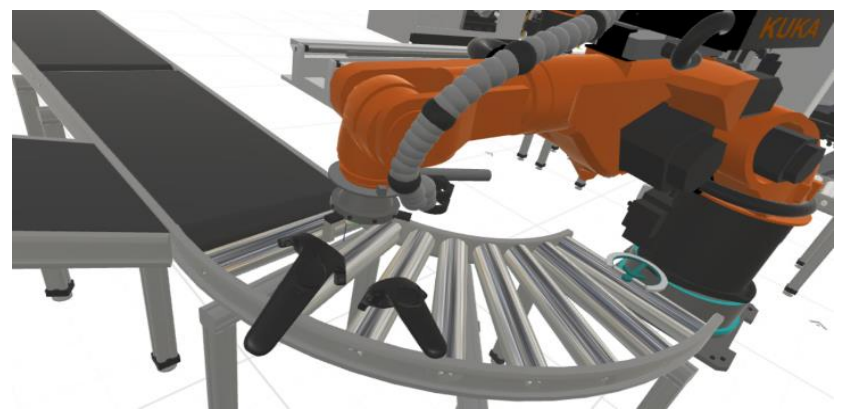

Figure 5. Verification of manipulator positions in the VR environment
In the individual parts of the simulation, a situation arises in which it is necessary to adapt the production workplace. The advantage of use of this software solution is the ability to customize certain parts in the production workplace without forcing the user to leave the virtual reality environment. These devices include particular conveyors. This allows user to resize them as needed. In the proposed production workplace, the size of the conveyor No. 2 was adjusted in this way. After moving to this conveyor in virtual reality, the control was aimed at the edge of the conveyor that was to be lengthened or shortened. After pressing and holding this button, together with the position of the controller, the length of the conveyor also changed as in Figure 6., where in the first part the conveyor No. 2 with the original dimension is shown and in the second part the conveyor No. 2 after adjustment of the length. The possibility of such an adjustment in the production workplace in a virtual reality environment allows to shorten the time of creating a feasible and functional production system. It is also possible to solve specific modifications in the part of the design of the production system directly with the client or with other departments without the need of performing complex tasks.
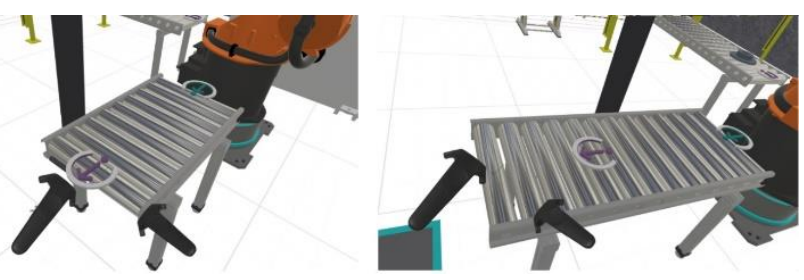

Figure 6. Adjusting the size of the conveyor

For a better idea of the manufactured part, CAD models of the brake disc in various stages of production were placed on the table of the workstation in the designed production workplace, with which it was possible to interact in a virtual environment. After running the simulation, the components behaved like their real-world physical equivalents. The models placed in this way can be grabbed using the button on the controller and viewed as shown in 
Figure 7. These models can be transferred using the controller and tested in various applications in the production workplace. One of them can be considered for example, the verification of the workpiece clamps in the production facility and to find out whether this tool is suitable for this particular model of the component located at this stage of production. If the product consists of several components that are assembled during the production operation, it is possible, after importing all the models, to create a whole configuration that can be assembled in a virtual reality environment. The controllers can be used to verify and subsequently eliminate problems that may arise during production. If a certain part of the product is composed in a real production system by a person, by testing its operation in a virtual reality environment, the ergonomics of the workplace can be improved and based on that, the optimal variant can be designed without the need for physical presence in the real system.

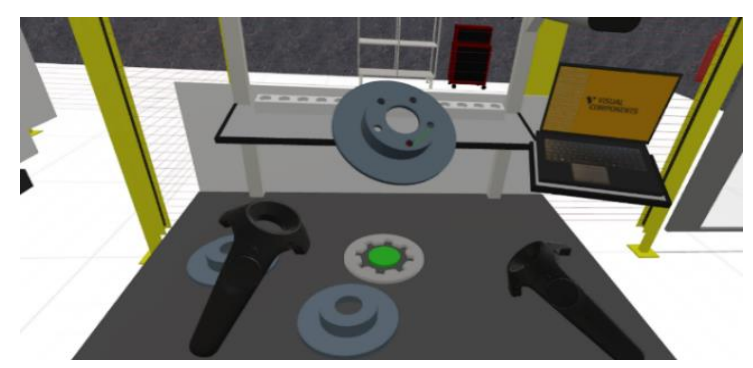

Figure 7. Interaction with the virtual component

An element is represented in the simulation that allows the designed production workplace to be stopped. In the proposed system, it represents the VR HMI interface, where the production workplace was stopped by the set signals after the interaction with the controller. In this case, it is not necessary to press any button on the controller to interact with the workplace. After pointing the button at the panels, the user moves the controller to turn the production site on and off during the running simulation as shown in Figure 8.

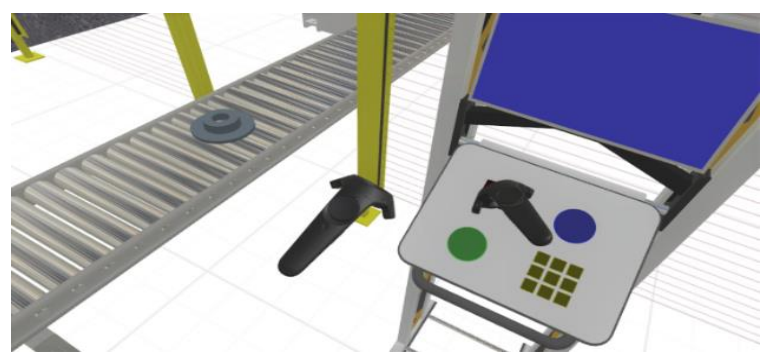

Figure 8. Interaction with a button that stops the production process

After changing the state of the workplace, the colour of the button is changed, which indicates that the production workplace is switched off. With this panel it is possible to assign various functions in virtual reality, for example as in the mentioned application. Another advantage is the possibility to connect this panel with a real program for a PLC device that serves as an input. It is thus possible to simulate and test the program of this device, which will manage a real production workplace. It is possible to optimize the workplace already in the design phase and thus verify the functionality and accuracy of this program, which can be modified according to the needs of the workplace in the appropriate connected software. The height of the buttons of this panel in the simulation of the designed production workplace can be adjusted to the user according to certain needs. This is done by grabbing the control panel and pressing and holding the grab button, where moving the control in virtual reality changes the height of the panel.

In order to capture as much as possible the essence of a real production workplace in virtual reality, the simulation also enables interaction with the production equipment itself. This was ensured by the possibility to also add to the interaction in the virtual environment separate elements of these devices, from which consisted the whole model of a device. In the proposed workcell, it was possible to interact with the panel of the drilling production machine as shown in Figure 9., with which after pressing the grip button on the controller, movement is allowed as in the environment of a real workplace. Based on this, it is possible to verify the operator's access to this panel in case of failure, or to verify whether this panel does not cause a collision with other parts of the production workplace.

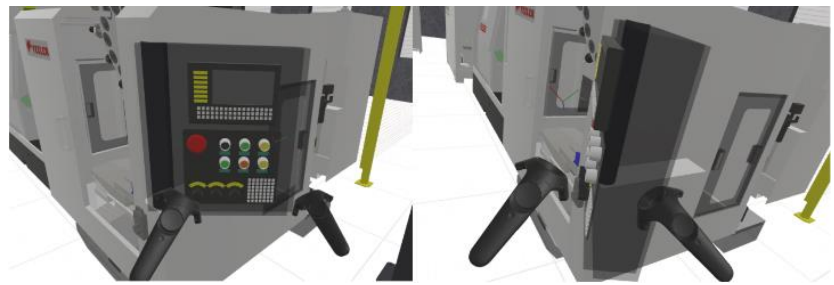

Figure 9. Interaction with the CNC machine control panel 
The designed production workplace can be explored using virtual reality from different angles as shown in Figure 10. The user's view resulting from the virtual reality of the production system can also be converted and visualized in the mobile application Visual Components Experience - Mobile Viewer. This allows you to view the shared design of the production system on your smartphone without the need to study the system from the drawing documentation. This facilitates the idea of the production system as a whole, which allows it to be better understood in less time. Such visualization makes it possible to further consult this design, either with the contracting authority or with other departments involved in the design of the production system. In this way, it is possible to avoid misunderstandings, shorten the design time and thus provide the most satisfactory solution.

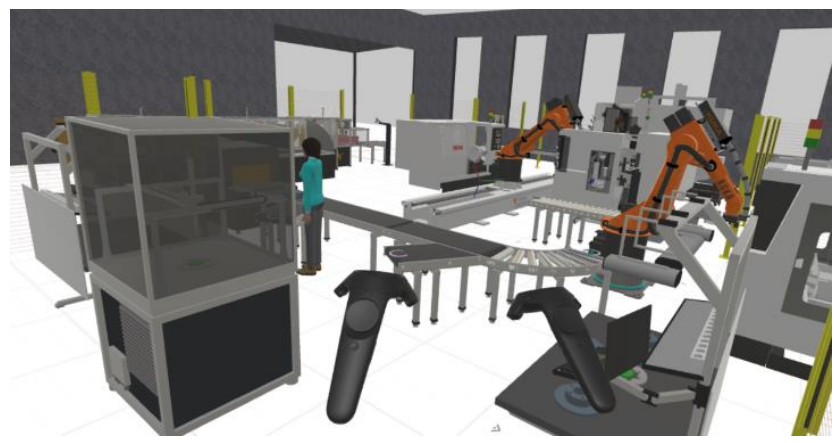

Figure 10. Simulation of draft production workplace in a virtual reality environment

\section{Conclusion}

Today, virtual reality can be considered as an important technology that has been implemented in the industrial environment and is also applied in various branches of production. It plays the most significant role especially in the visualization of simulated production processes. Its use leads to increased efficiency, flexibility and reduced costs in the implementation of either new or existing production systems. It is possible to use it from very design of the production system to its actual construction. In this paper, based on the main principles of virtual reality technology and simulation, which can be considered as an input source of information, a visualization of the production workplace in a virtual environment was created. It also describes various other applications of this technology and their use in industry.

\section{Acknowledgements}

This article was supported by the Ministry of education of Slovak Republic for supporting this research by the grant KEGA 004TUKE-4/2020 and VEGA 1/0051/20.

\section{References}

[1]. Zhong, Y., \& Shirinzadeh, B. (2008). Virtual factory for manufacturing process visualization. Complexity International, 12(1), 1-22.

[2]. Novak-Marcincin, J., \& Novakova-Marcincinova, L. (2013). Application of Augmented Reality Technologies in Virtual Manufacturing. Academic Journal of Manufacturing Engineering, 11(4).

[3]. Spasova, N., \& Ivanova, M. (2020). Towards Augmented Reality Technology In Cad/Cam Systems And Engineering Education. In The International Scientific Conference eLearning and Software for Education (Vol. 2, pp. 496-503). " Carol I" National Defence University.

[4]. Nee, A. Y., \& Ong, S. K. (2013). Virtual and augmented reality applications in manufacturing. IFAC proceedings volumes, 46(9), 15-26.

[5]. Havard, V., Jeanne, B., Lacomblez, M., \& Baudry, D. (2019). Digital twin and virtual reality: a cosimulation environment for design and assessment of industrial workstations. Production \& Manufacturing Research, 7(1), 472-489.

[6]. Dobránsky, J., Kočiško, M., Baron, P., Simkulet, V., Běhálek, L., Vojnová, E., \& Nováková-Marcinčinová, L. (2016). Evaluation of the impact energy of the samples produced by the additive manufacturing technology. Metalurgija, 55(3), 477-480.

[7]. Jamali, S. S., Shiratuddin, M. F., \& Wong, K. W. (2013). A review of augmented reality (AR) and mobile-augmented reality (mAR) technology Learning in tertiary education. Learning in Higher Education, 20(2), 37-54.

[8]. Gabajova, G., Furmannova, B., Medvecka, I., Grznar, P., Krajčovič, M., \& Furmann, R. (2019). Virtual training application by use of augmented and virtual reality under university technology enhanced learning in Slovakia. Sustainability, 11(23), 6677.

[9]. Kuric, I., Bulej, V., Saga, M., \& Pokorny, P. (2017). Development of simulation software for mobile robot path planning within multilayer map system based on metric and topological maps. International journal of advanced robotic systems, 14(6), 1729881417743029.

[10]. Kočiško, M., Novák-Marcinčin, J., Baron, P., \& Dobránsky, J. (2012). Utilization of progressive simulation software for optimization of production systems in the area of small and medium companies. Tehnički vjesnik, 19(4), 983-986.

[11]. Dupláková, D., Hatala, M., Knapčíková, L., Radchenko, S., \& Duplák, J. (2019). Possibilities of Inadequate Physical Load Reduction by Ergonomic Rationalization of Working Environment. Walailak Journal of Science and Technology (WJST), 16(12), 985-995.

[12]. Sapietová, A., Saga, M., Kuric, I., \& Václav, Š. (2018). Application of optimization algorithms for robot systems designing. International journal of advanced robotic systems, 15(1). 